\title{
Desarrollo curricular de la Educación Física en la Educación Infantil
}

\author{
Por: Gil Madrona, P. (coord.) (2013) \\ Madrid: Ediciones Pirámide.
}

Amparo Romero ${ }^{1}$ 
En el libro Desarrollo curricular de la Educación Física en la Educación Infantil, se presentan una serie de ideas, una propuesta de programación, herramientas didácticas, metodológicas y de evaluación, que conforman un modelo didáctico que será de utilidad para todo el profesorado de educación infantil y de educación física en la etapa de educación infantil, con la finalidad de favorecer un entorno adecuado en el que los niños desarrollen armónicamente su cuerpo, como instrumento para alcanzar la madurez y una adecuada autoestima. En el libro se muestra de forma detallada la relevancia del trabajo de la educación física en la etapa de educación infantil, ámbito adecuado para el cultivo y desarrollo de actitudes positivas y de valores individuales y sociales de gran importancia.

El libro elaborado por profesores de diferentes universidades españolas, es un texto que nace con una clara vocación docente, coordinado por el profesor Pedro Gil Madrona, argumenta que la educación física en la educación infantil, permite observar y trabajar, además de los aspectos perceptivo-motores y físico-motores, variables tan esenciales en los niños como la creatividad, la confianza en sí mismos, el nivel de autoestima y la capacidad para estar en lugares compartidos.

El texto recoge de forma inexorable una reseña histórica de la infancia y de la educación infantil, de los diferentes modelos didácticos más relevantes en educación infantil, y de cuál es el papel que ocupa la educación física en la actual educación infantil. La psicomotricidad su evolución y corrientes es el segundo capítulo de la obra. A continuación presenta los modelos de clase y la organización de las actividades de enseñanza/aprendizaje de educación física en educación infantil. Este capítulo da paso a otros, en los que se aborda la planificación educativa de la educación física en la educación infantil y el diseño curricular de la educación física en la educación infantil. Siguiendo ese hilo conductor, dedica un capitulo para abordar la metodología docente, otro al juego motor en la educación física en esta etapa educativa, otro al cuento motor como recurso didáctico y otro más dedicado a la evaluación de la educación física en la etapa de educación infantil. El texto, en su clara vocación docente, concluye con un último capítulo denominado "Conexión entre la teoría y la práctica de la educación física en educación infantil: unidad didáctica globalizada 'las profesiones y oficios', en donde se presenta un ejemplo de concreción práctica, de cómo se diseña y se enseña la educación física en la etapa educativa de la educación infantil.

Los autores de este libro consideran esencial la creación de un clima seguro y afectivo para el niño, pues ayudará de manera directa al logro de una autoestima positiva y al desarrollo de una personalidad equilibrada. La educación del movimiento, en la educación infantil, es implementada a través de métodos de trabajo basados en la experimentación, la actividad y el juego. En el libro se pone de manifiesto qué es el juego y los cuentos motores son el medio idóneo para trabajar con los niños, pues permite los aprendizajes significativos de forma globalizada, y 
Desarrollo curricular de la Educación Física en la Educación Infantil. Por: Gil Madrona, P. (coord.) (2013). Madrid: Ediciones Pirámide.

favorece la enseñanza activa. El juego se plantea como un contenido de aprendizaje, con objetivos motrices, afectivos y sociales. Por otro lado, el juego es considerado una estrategia metodológica, y se plantea como medio para alcanzar el desarrollo de la unidad didáctica. Las dos cuestiones se aúnan en un fin común, el enfoque globalizador e integrador esencial en esta etapa educativa.

En el texto hace hincapié en el hecho de que la evaluación de la motricidad y la educación física ha de tener un carácter global, continuo y formativo. Asimismo, debe servir para valorar el proceso de aprendizaje y proporcionar datos relevantes para tomar decisiones individualizadas.

El libro nos indica qué es lo que hay que tener en cuenta al hacer una evaluación en educación física infantil y el cómo hacerlo. El área más relacionada con el ámbito de la motricidad es el conocimiento de sí mismo y autonomía personal, ya que todo el esquema corporal, lateralidad y equilibrio están íntimamente ligados a esa área. No obstante, el conocimiento del entorno y lenguajes: comunicación y representación, también están relacionados, aunque de forma más transversal: percepción espaciotemporal, expresión corporal, etc. En relación al cuándo evaluar, la evaluación en educación física infantil, se debe llevar a cabo en varios momentos del período educativo. Una primera evaluación es la llamada evaluación inicial y es la que tiene lugar cuando el niño accede por primera vez a la clase. Posteriormente, tendrá lugar la evaluación continua o formativa, que tratará de ver los progresos, dificultades y necesidades del alumno. Por último, existe la llamada evaluación final, que es la que tiene lugar una vez se ha finalizado todo el proceso educativo, bien sea al final del curso o de la etapa. Los autores nos ilustran sobre cómo evaluar, apuestan por una combinación en la que se puedan registrar datos cuantitativos y, por tanto, numéricos y datos cualitativos donde el profesor pueda hacer observaciones de tipo subjetivo. Para poder llevar a cabo de forma efectiva esa observación, el docente tendrá que contar con unas hojas de registro donde pueda anotar todos aquellos datos que le permitan realizar dicha evaluación.

Este libro aporta, como indican las personalidades que lo prologan, Ismael Sanz Labrador, (Director del Instituto Nacional de Evaluación Educativa, INEE, Dirección General de Evaluación y Cooperación Territorial Ministerio de Educación, Cultura y Deporte) y la profesora Arlette Perry (Universidad de Miami. E.E.U.U Directora del Departamento de Kinesiología y Ciencias del Deporte y del laboratorio de Fisiología Clínica y Aplicada), ellos anotan que es un enfoque imprescindible para los futuros docentes en educación física en la etapa de educación infantil, una sólida herramienta-guía en la apasionante labor del enseñante y también que contribuirá en el desarrollo armónico de la personalidad de los niños. De ahí, que se insté a los profesores, a los maestros, a los educadores físicos y administradores a obtener este libro, a leerlo e incluirlo en su currículo. 
Reseñas

Resumiendo el libro da cuenta del papel de la educación física en el marco de la educación infantil y centra su atención en los contenidos que se enseñan desde la educación física y en el cómo se enseñan en la etapa de educación infantil. 